\title{
EXPERIMENTAL STUDY ON THE PERFORMANCE OF SLANT END-PLATE CONNECTIONS AT ELEVATED TEMPERATURE
}

\author{
Farshad Zahmatkesh ${ }^{1,}{ }^{*}$, Mohd. H. Osman ${ }^{2}$, Elnaz Talebi ${ }^{3}$, \\ Ahmad Kueh ${ }^{3}$ and Mahmood Tahir ${ }^{3}$ \\ ${ }^{1}$ Pennsylvania Housing Research Centre (PHRC), Department of Architectural Engineering, \\ Pennsylvania State University, University Park, PA, 16801, USA \\ ${ }^{2}$ UTM Forensic Engineering Centre, Faculty of Civil Engineering, \\ Universiti Teknologi Malaysia, 81310 UTM Johor Bahru, Johor, Malaysia \\ ${ }^{3}$ Construction Research Centre (CRC), Faculty of Civil Engineering, \\ Universiti Teknologi Malaysia, 81310 UTM Johor Bahru, Johor, Malaysia \\ *(Corresponding author: E-mail:_fa_zahmatkesh@yahoo.com)
}

Received: 24 January 2016; Revised:23 March 2017; Accepted: 25 March 2017

\begin{abstract}
Axially restrained steel beams exhibit lower structural efficiency when they are subjected to elevated temperature. Thermal expansion is one of the most hazardous conditions such beams could experience throughout their service life. In this regard, using an adequately performing connection can enhance the thermal performance of the beams. This paper, therefore, evaluates experimentally the performance of slant end-plate as a proposed connection for dissipating thermal expansion experienced by the steel beam. In this study, several experimental tests were carried out on two different specimens in terms of scaling and gravity loads to prove the hypothesis and results obtained from a present analytical study. The evaluation of tests and analytical results showed that both outcomes are consistent with each other with comparison ratios between 0.96 and 1.09 . In addition, the experimental tests, as well as analytical outcomes, have proven that the slant end-plate connection can successfully reduce the additional thermally induced axial forces via the upward crawling mechanism.
\end{abstract}

Keywords: Slant end-plate connection, elevated temperature, gravity load, experimental test, analytical model

DOI: $10.18057 /$ IJASC.2018.14.1.4

\section{INTRODUCTION}

Thermal effects are well-known as among the most harmful loading types any steel structure can experience throughout its service life. With ever-developing large cities and limited space available for buildings, it is inevitable that structures grow in an upward fashion. As a result, the risk of thermal hazard increases as well. Thus far, it is well documented that thermal loading has a significant influence on steel structural components. Elevated temperature can induce an extra axial force in structural members. One most common thermal effect identified in steel structures is the reduction in compressive strength due to increase in temperature. Rodrigues et al. [1] found that the thermal failure of a structural element occurs in two major stages: linear and nonlinear. They posited that the first stage constitutes the initiation mechanism of failure, involving the yielding of members before the inelastic regime and the reduction of Young's modulus. Mourão and Silva [2] investigated the expansion of steel beams caused by uniformly elevated temperatures and illustrated that in an axially restrained beam, the end supports resist against thermal expansion. Wong [3] demonstrated that the strength of a steel beam at room temperature is acceptable for design regardless of the existence of axially restrained boundary conditions or otherwise. 
The search for an economical resistance method to improve the performance of steel structures in the presence of elevated temperature remains a challenging task that captures the interest of structural engineers. Research on steel structures with the confinement of axial expansion in restrained beams has been quite intensive since the early 2000s. Commonly employed engineering solutions, which address temperature-related concerns, take the form of section area increment, provision of lateral supports [4], cooling action by air-conditioning and watering [5], and thermal breaks [6].

A considerable amount of literature has been published on the structural response of steel beams under initially induced thermal axial forces [7-9]. In addition, a number of studies have investigated end-plate connections at elevated temperatures [10-15]. However, there is so far no adequate evidence showing the existence of a reliable structural method to reduce the axial force in restrained beams subjected to elevated temperature. In the present work, we propose to explore further by experimental means slanted end-plate connections as a structural solution to protect beam and connections against primary failure in the presence of elevated temperature. The fundamental development in terms of an analytical model for such a connection when subjected to a non-symmetric gravity load and a temperature increase has been formulated by Zahmatkesh et al. [16]. They demonstrated that a temperature increase in a steel beam with conventional connections induces a huge additional axial force that decreases the beam ability to bear external gravity loads. Besides, this study shows that by changing the connection to that of the slanting type, this additional axial force can be dissipated efficiently.

\section{VERTICAL AND SLANT END-PLATE CONNECTIONS CHARACTERISTICS AT ELEVATED TEMPERATURE}

The popularity of end-plate connections is largely owed to their simplicity in fabrication and installation. Figure 1 shows the typical conventional (vertical) and slant end-plate connections. In general, these connections consist of end-plates that are welded to the ends of a beam in the workshop and then bolted to the flange of columns on site. They can be utilised with slanted beams and are able to tolerate moderate offsets in the beam to column joints. The current study has focused on the slant end-plate connection as a proposed thermal resistance connection. The slant end-plate connection is similar to conventional end-plate connections, differing only in the inclination angle of the end-plate as shown in Figure 1. In the currently investigated experimental tests, the angle of slanting of the end-plate is set to $45^{\circ}$, as it is a practical angle for installing bolts into the holes at the top and bottom of the end-plate.

In elevated temperature conditions, when a steel beam is heated, it tends to expand. Therefore, if the supports resist this expansion, an additional axial force is generated in the beam. Usually, the thermal elongation $(\Delta L)$ of the steel beams is very small in the elastic range of material. Zahmatkesh et al. [17] demonstrated that the use of slant end-plates instead of conventional (vertical) connections can lead to a dissipation of the generated thermal axial force. Equations 1 to 4 determine the value of axial force $(P)$ in an axially restrained steel beam with slant end-plate connections under various loading conditions.

Under symmetric gravity load and before elevated temperature:

$P_{i}=\frac{W L}{2} \cot (\theta+\phi)$ 

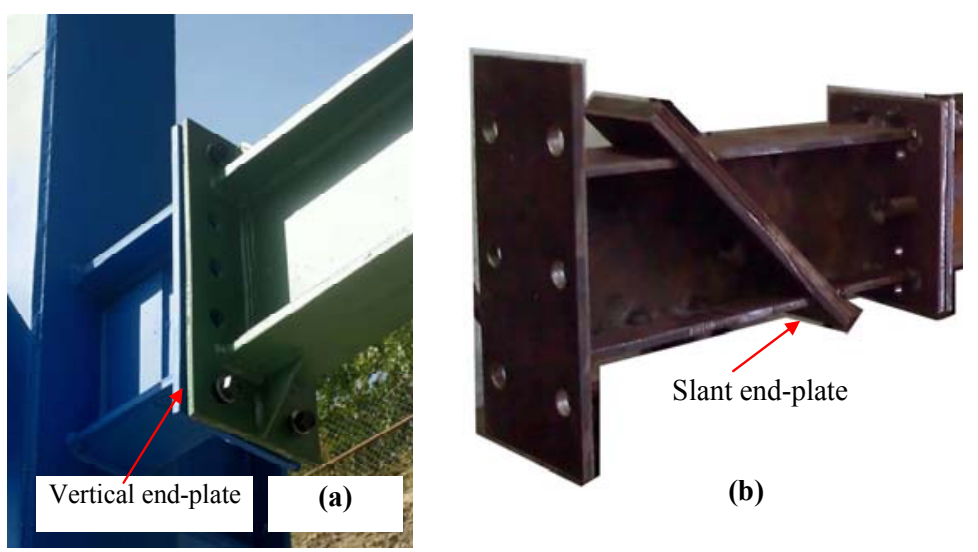

Figure 1. Typical (a) Vertical and (b) Slant Bolted End-plate Connections

Under non-symmetric gravity load, before sliding and before elevated temperature:

$P_{i}=(a W L) \cot (\theta+\phi)$

Under non-symmetric gravity load, after sliding and before elevated temperature:

$P_{i}=\frac{W L\left(\cos ^{2} \theta-\sin ^{2} \phi\right)}{\sin 2 \theta}$

After elevated temperature for both cases of gravity loads:

$$
P_{t(m)}=\frac{W L}{2} \cot (\theta-\phi)
$$

where $W$ is the linear uniform gravity load along the length of steel beam $(L), a$ is the slanting angle, $\varnothing$ is the friction angle between slant end-plates based on the Coulomb model, and $a$ is the distance of the resultant of non-symmetric gravity load to support. The thermal force dissipation mechanism involves an upward crawling of the connections inclined surfaces at the end of the steel beam as a result of expansion. The behaviour of a restrained steel beam with vertical and slant end-plate connections under temperature increase are shown in Figures 2 and 3, respectively. As shown in Figure 2, after an increase in temperature, the conventional (vertical) connections resist against expansion of the beam and it is buckled because the beam could not tolerate an extra axial load $\left(P_{c r}\right)$. On the other hand, Figure 3 illustrates that, after an elevation in temperature, two inclined supports induce thermal axial force into the steel beam through member expansion. However, the two slanted surfaces allow the beam to dissipate the thermal axial force and expansion by linear crawling on the two inclined plates. Although there is a vertical motion tolerance between the surfaces in the conventional (vertical) endplate connections, it is unable to absorb the overall thermal expansion at the two ends of the beam in the horizontal direction. This is because the direction of thermal expansion is perpendicular to the direction of the moving surface. In the slant end-plate connection, there is a slanting tolerance between the surfaces to absorb the thermal elongation of the beam using the crawling mechanism over the slanting faces. Therefore, the direction of horizontal expansion can be projected to the slanting plane of the connection. 


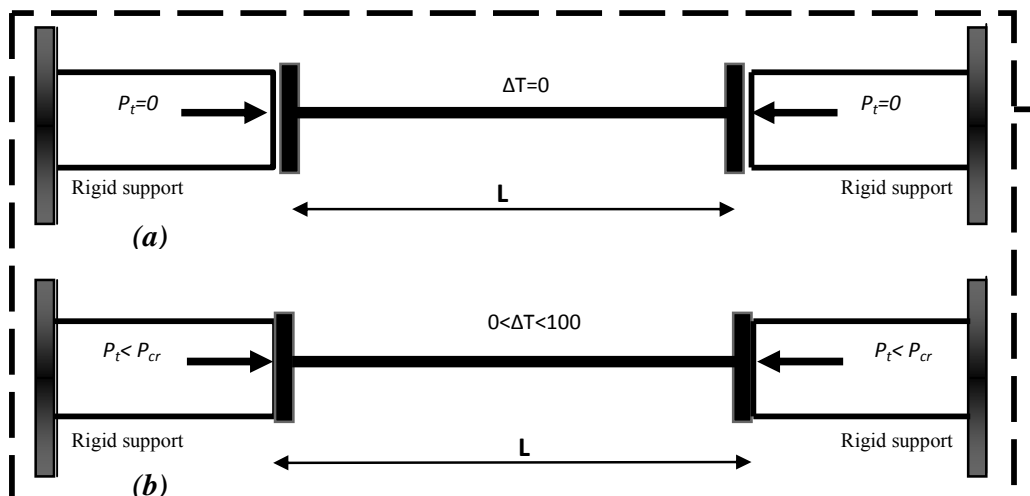
a) Stage1-Beam connections

temperature,

b) Stage2-Beam connection

after increase in temperature

(two end-plates are in

contact)

c) Stage3-Beam connection

after increase in temperature

(buckling and decrease in

Young's modulus due to

(b) d) Stage4- Temperature -

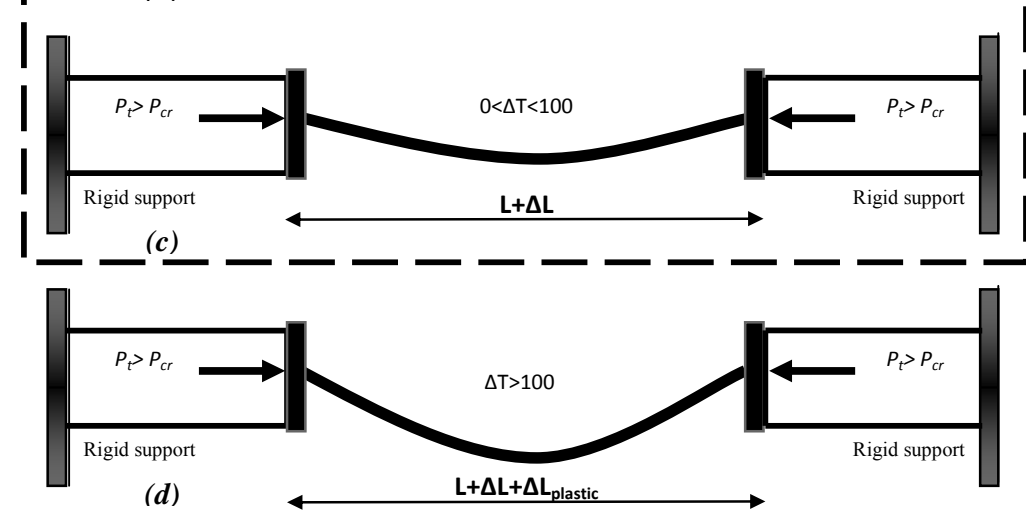

increase that is higher than

$100{ }^{\circ} \mathrm{C}$ (decrease in Young's

modulus due to a change in

material properties and axial

forces).

Figure 2. Beam with Vertical Bolted End-plate Connection subjected to Temperature Increase
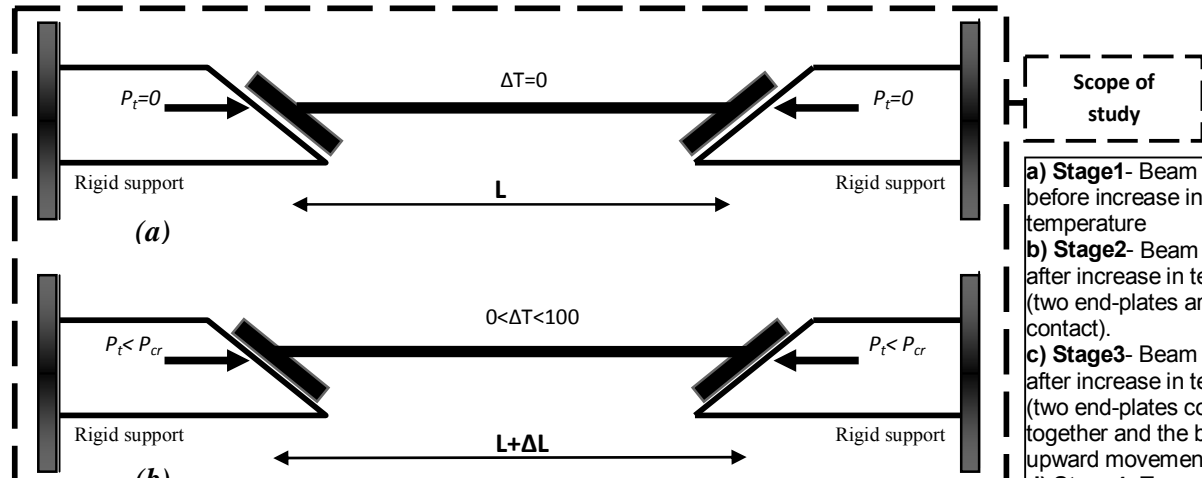

a) Stage1- Beam behavior

before increase in

temperature

b) Stage2- Beam behavior

after increase in temperature

after increase in tempe
(two end-plates are in

contact).

c) Stage3- Beam behavior

after increase in temperature

(two end-plates contact

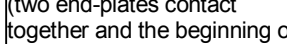

upward movement)

d) Stage4- Temperature-

(b)

increase that is higher than

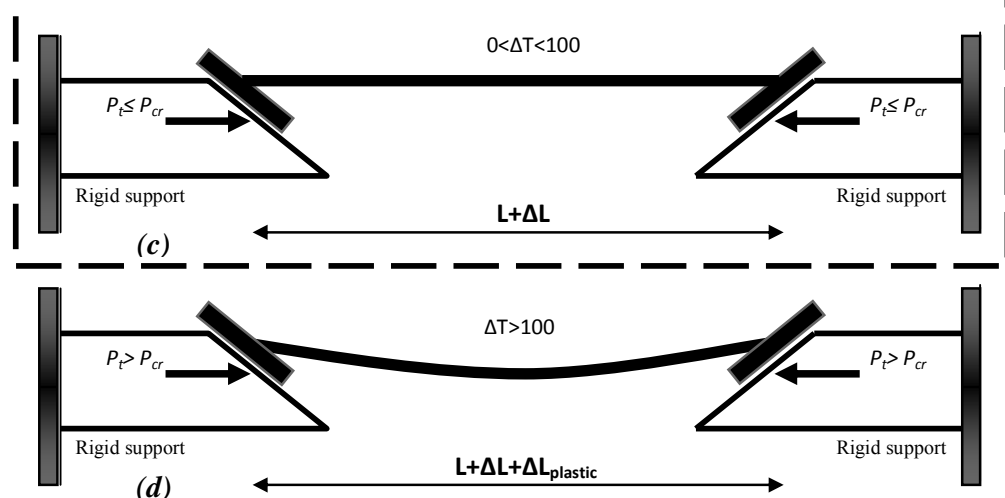

$100^{\circ} \mathrm{C}$ (decrease in Youn
modulus due to material

properties deterioration).

(d)

Figure 3. Beam with Slant Bolted End-plate Connection subjected to Temperature Increase 


\section{EXPERIMENTAL STUDY}

To validate the results of the analytical method used by Zahmatkesh et al. [17], two cases were of interest: i) small-scale and ii) full-scale specimens. Table 1 lists the material properties of steel beams used in this study.

Table 1. Material Properties of Steel Beam

\begin{tabular}{|c|c|c|c|c|c|c|}
\hline $\begin{array}{c}\text { Material } \\
\text { type }\end{array}$ & $\begin{array}{c}\text { Yield } \\
\text { stress } \\
{[\mathrm{MPa}]}\end{array}$ & $\begin{array}{c}\text { Ultimate } \\
\text { stress } \\
{[\mathrm{MPa}]}\end{array}$ & $\begin{array}{c}\text { Density } \\
{[\mathrm{kg} /} \\
\left.\mathrm{m}^{3}\right]\end{array}$ & $\begin{array}{c}\text { Young's } \\
\text { modulus } \\
{[\mathrm{GPa}]}\end{array}$ & $\begin{array}{c}\text { Linear } \\
\text { coefficient } \\
\text { of thermal } \\
\text { expansion }\end{array}$ & $\begin{array}{c}\text { Poisson's } \\
\text { ratio }\end{array}$ \\
\hline St37 & 240 & 370 & 7850 & 200 & $1.5 \mathrm{e}-5$ & 0.3 \\
\hline
\end{tabular}

\subsection{Small-Scale Specimen}

\subsubsection{Symmetric gravity load test}

The structural responses computed by the analytical approach were first compared with the experimental tests on the small-scale specimen. Experimental data were taken from the smallscale steel beam tests carried out at the Structure Lab of the Universiti Teknologi Malaysia (UTM). The geometrical details of the considered structure are shown in Figure 4. The section of the specimen was of $\mathrm{H}$ shape with a thickness of $1.5 \mathrm{~mm}$. The columns height and the beam length were $235 \mathrm{~mm}$ and $450 \mathrm{~mm}$, respectively (the middle beam was $350 \mathrm{~mm}$ long). Figure 5 shows the composition of components used for the small-scale specimen test. The structural members of this specimen consist of five separate parts: the beam specimen with inclined ends supported by a corbel beam at each end and two columns. These five parts were assembled with normal bolts and nuts. To conduct the tests, the beam was detached as a separate component from the supporting frame, resembling those of the analytical assumptions [17].

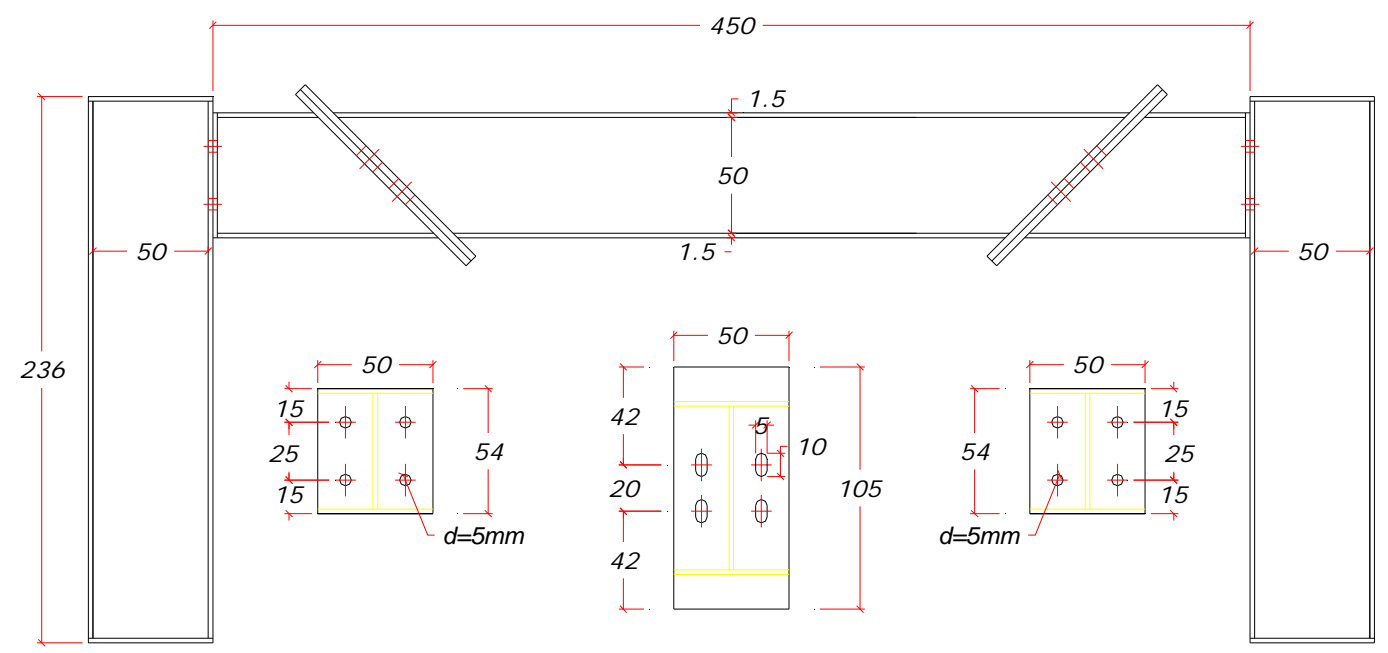

Figure 4. Geometrical Details of the Steel Beam with Slant End-plate Connection for Experimental Study (Small-scale Specimen). All Units are in mm 


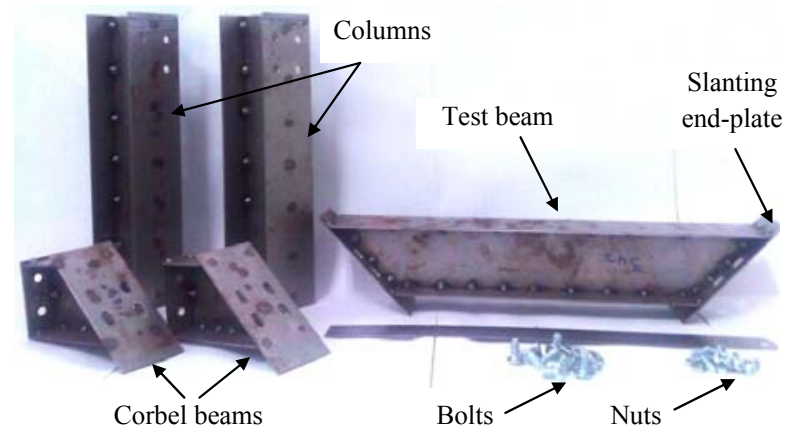

Figure 5. Parts of a Steel Frame with Slant End-plate Connection (Small-scale Specimen)

In line with the primary assumptions, the axially restrained steel beam was connected to the end supports by a slider system. As a result, oversize holes with clearance for bolts movement were considered for free sliding of the beam on the inclined end-supports, as in the primary assumptions. For this reason, four oval shape holes (slot) have been provided for free sliding of the beam on the slanted supports. The tightened normal bolts had been restricted for plane displacement but they were free for sliding on the inclined supports. Conforming to the analytical equations, the friction factor, $\mu_{\mathrm{s}}$, between two faces of the slant end-plate connection was required. Figure 6 shows a basic friction test set-up for determining the friction factor between the inclined steel plates. The self-weight of the beam was $6.67 \mathrm{~N}$ with a connection slanting angle of $45^{\circ}\left(\theta=45^{\circ}\right)$. As shown in Figure 6 a $39.22 \mathrm{~N}$ weight had been placed at the end of the left side beam in the vertical direction. To measure the sliding force, a load cell with $5 \mathrm{kN}$ capacity had been located at the side of the beam. A data logger (UCAM70A) had been used to measure the corresponding axial force. The static friction coefficient was found to be $0.37\left(\mu_{s}=\tan \varphi\right)$ from the test.
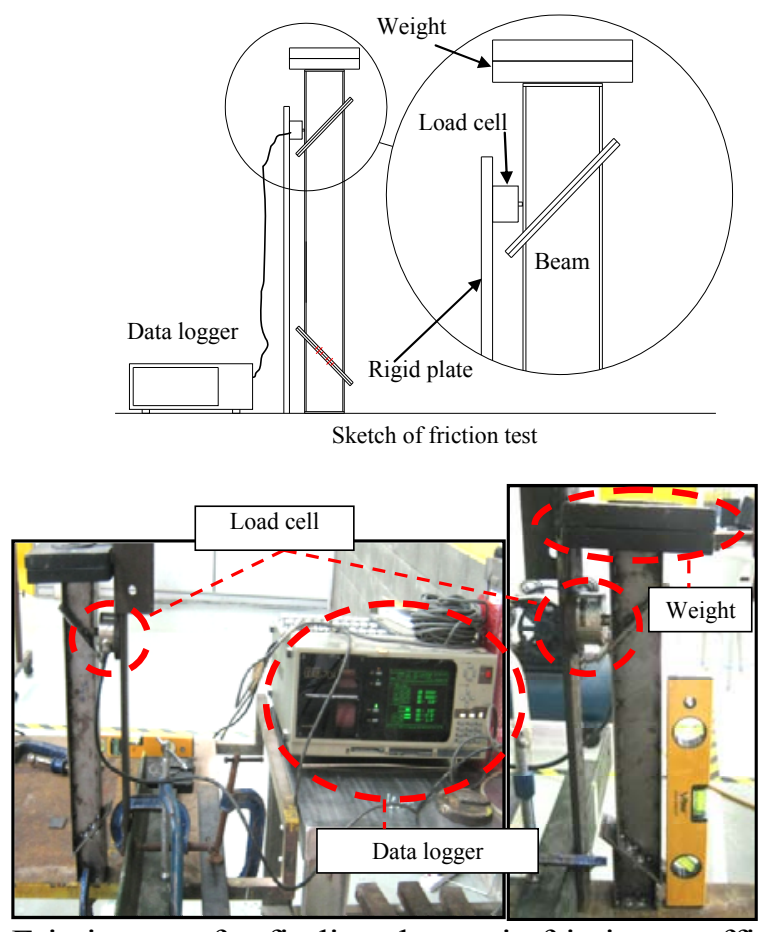

Figure 6. Friction test for finding the static friction coefficient $\left(\mu_{s}\right)$ between two faces of slant end-plate connection (small-scale specimen) 
After determining the friction coefficient, the small-scale specimens were tested at room and elevated temperatures conditions. The tests were designed with the aim of verifying the performance of the slant connection as well as the analytical method. Figure 7 shows the test set-up for the small-scale specimen. In the conducted tests, the values of axial force in the beam due to elevated temperature and seven symmetric gravity load intensities $(6.67 \mathrm{~N}, 26.29$ $\mathrm{N}, 45.91 \mathrm{~N}, 65.53 \mathrm{~N}, 85.15 \mathrm{~N}, 104.77 \mathrm{~N}$ and $124.39 \mathrm{~N}$ ) were recorded.
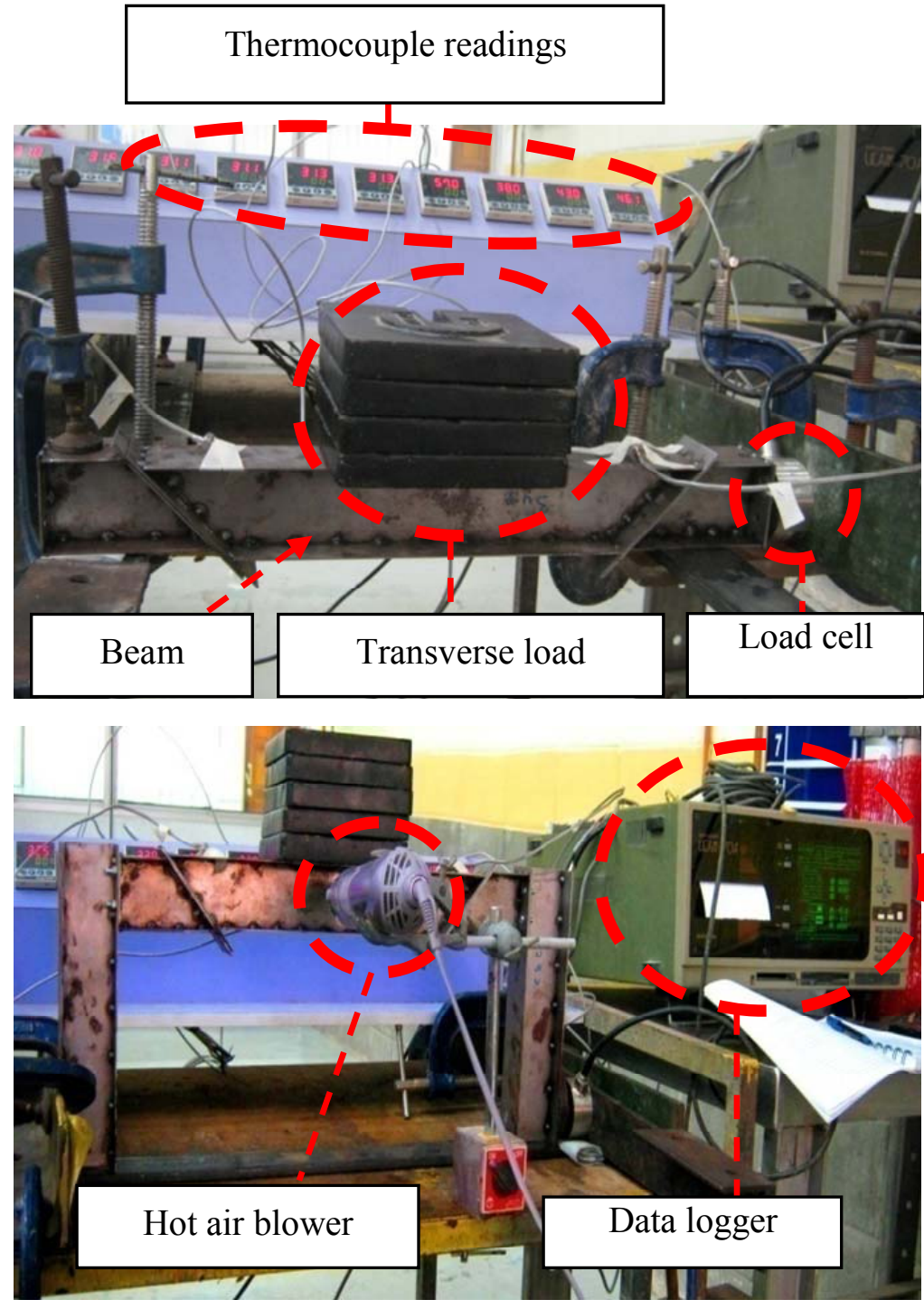

Figure 7. Test set-up for Small-scale Specimen under Symmetric Gravity Load

Similar to the friction test, the axial force was recorded with the data logger and a load cell located at the end of the beam. To keep the temperature under $100^{\circ}$ or within elastic zone [18], 10 thermocouples were attached along the beam with the heat source coming from a hot air blower placed in the middle of the beam. Note that only some key outcomes of the analytical method are considered for comparison with the experimental responses. Figure 8 shows the relationships between gravity loads and axial forces $\left(P_{i}\right.$ and $\left.P_{t}\right)$ in the beam for two case studies, before and after elevated temperatures. It is evidenced that the analytical models 
conform acceptably to the outcomes produced by experiments, both before and after temperature increase, thus reflecting the consistency of both methods.

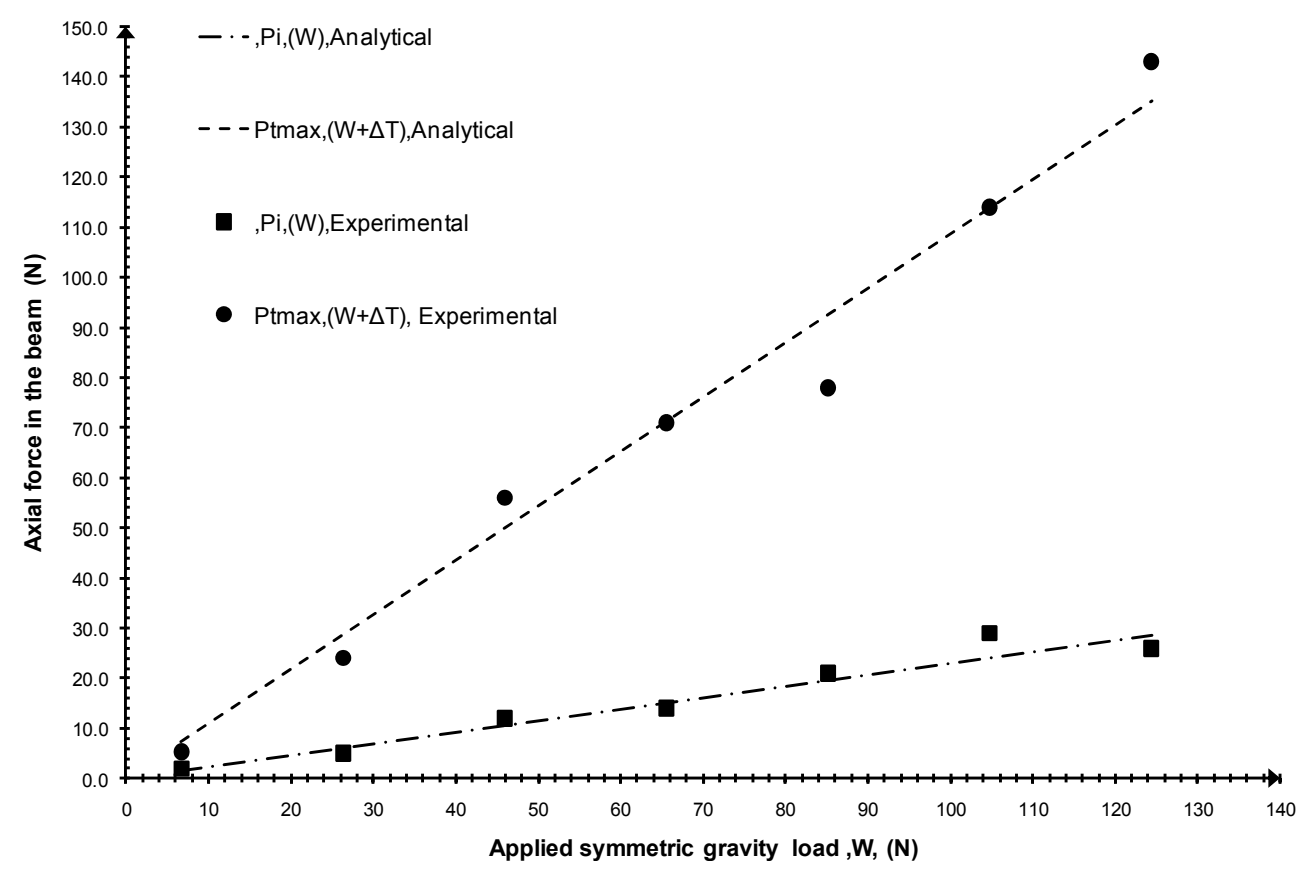

Figure 8. Relationship between Symmetric Gravity Load and induced Axial Force in the Beam in Small-scale Specimen (friction factor, $\mu_{s}=\tan \Phi=0.37, \theta=45^{\circ}$ )

\subsubsection{Non-symmetric gravity load test}

In the second stage, the small-scale specimen was tested under non-symmetric gravity loads. In the non-symmetric load case study, the distance between slant support and the resultant vector of gravity load is a.L where $L$ is the length of the beam (Figure 9). Based on Equation (5) [19], the values of $a$ factor can be determined for both before and after sliding cases. The obtained $a$ factors for the cases before and after sliding were 0.688 and 0.878 , respectively.

$\mathrm{a} \leq \frac{\cot (\theta-\phi)}{\cot (\theta+\phi)+\cot (\theta-\phi)} \quad$ Equilibrium condition before sliding

The beam was tested for several incrementally applied non-symmetric gravity loads with three sub-cases: before (two cases) and after elevated temperatures. Figure 9 shows the test set-up for both cases, i.e., before and after sliding. During the test, the axial force was recorded with a force sensor located at the end of the beam that was connected to an interface kit system (model 8/8) attached to a computer. The distances from the centre of mass of gravity load to the right support were $0.688 \mathrm{~L}$ and $0.878 \mathrm{~L}$, respectively. 


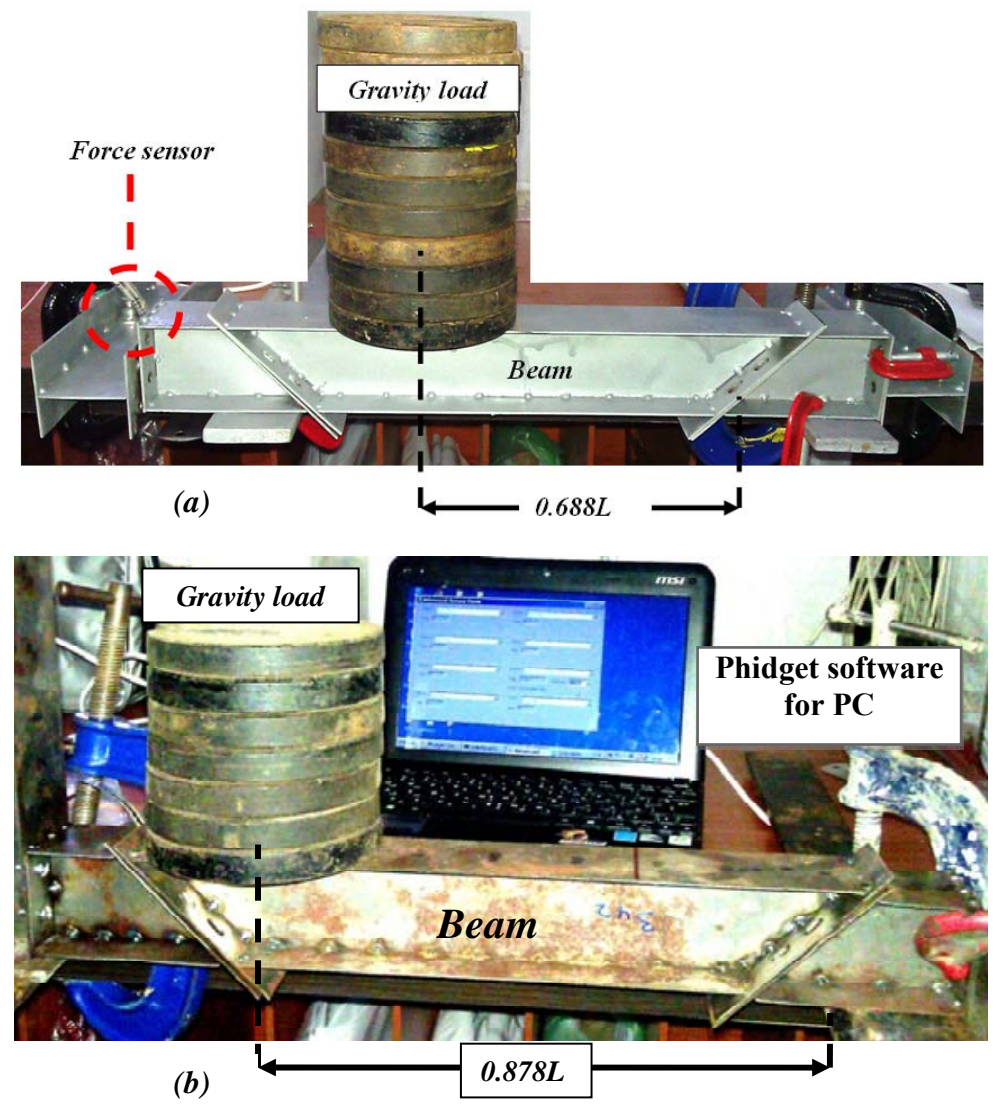

Figure 9. Test Set-up at Room Temperature for Two Case Studies a) before sliding, $a=0.688$ and $\mathrm{b}$ ) after sliding, $a=0.878$

In the case of after elevated temperature, a 10-channel thermocouple set was used for measuring the applied temperature with the heat source coming from a hot air blower placed in the middle of the beam. The aim was the same, i.e., to measure the axial force in the beam for incremental load magnitudes. In compliance with the experiment, the results obtained from the analytical approach (the small-scale specimen modelling) were used for comparison. Figure 10 shows the relationships between applied non-symmetric gravity loads and axial forces in the small-scale specimens for all cases of sliding and temperature conditions. The trend exhibited by the experimental test is reasonably similar to that of the analytical method. It is apparent that in both methods, the axial force in the beam increased with the nonsymmetric gravity load.

As shown in Figure 10, after the initiation of primary sliding on the inclined surface, an increase in temperature did not change the axial force. Because of limitations imposed on the experimental study, only some of the important features were chosen for testing (for example, it would have been somewhat laborious to change the friction factor to cover all cases). Results indicate that the model agrees well with the experimental findings, both with and without temperature change. 


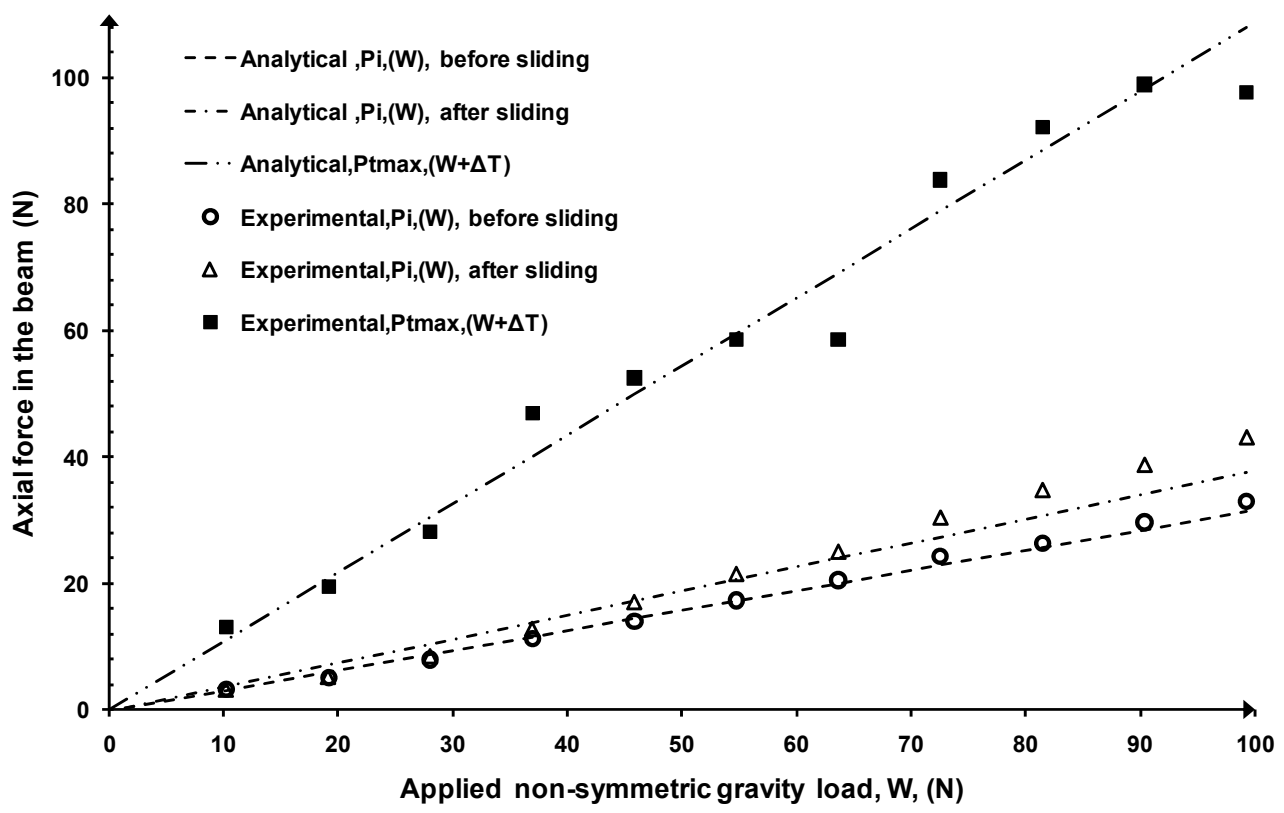

Figure 10. Relationship between Non-symmetric Gravity Load and Axial Force in the Small-scale Specimen (friction factor, $\mu \mathrm{s}=\tan \varphi=0.37, \theta=45^{\circ}$ )

\subsection{Full-Scale Specimen}

\subsubsection{Symmetric gravity load test}

Next, the thermal performance of a full-scale specimen with slant end-plate connections was investigated by experimental tests where the direction of supports slanting angle had been fixed at $45^{\circ}$. Again, the structural responses computed by the analytical method were used for comparison. The geometrical details of the structure are shown in Figure 11. As shown in this figure, the main and side beams were of I sections with a thickness of $6 \mathrm{~mm}$ for webs and 8 $\mathrm{mm}$ for flanges. The length of the beam was $1800 \mathrm{~mm}$. Figure 12 shows the composition of components used for the full-scale specimen test. The structural components of this specimen consist of five separate parts: the test beam with slanting ends and two short side beams. These five parts were assembled by normal bolts and nuts.

For the tests, the side beams and middle beam were attached as a connected member of the whole specimen, similarly to the analytical assumptions. According to the analytical hypothesis, the axially restrained steel beam is connected by a sliding connection system. Therefore, slot holes were considered in the specimen for free sliding of the beam on the inclined supports. 

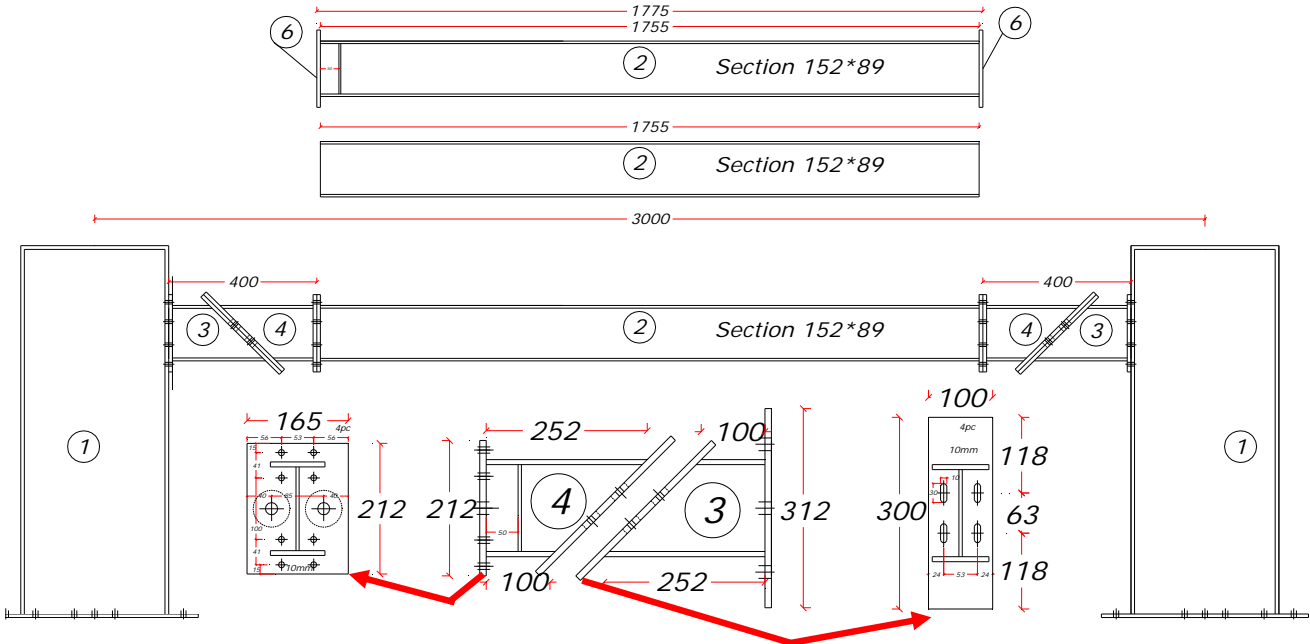

Figure 11. Geometrical details of the Steel Beam with Slant End-plate Connection for Experimental Study (Full-scale Specimen). All Units are in $\mathrm{mm}$

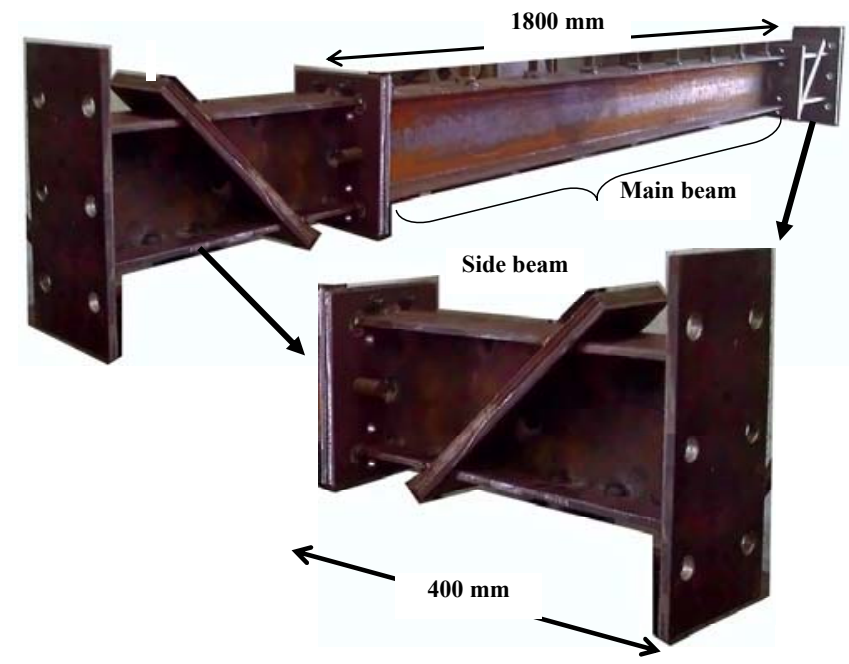

Figure 12. Parts of the Steel Beam with $45^{\circ}$ Slant End-plate Connection (Full-scale Specimen)

For the current test, the friction factor, $\mu_{\mathrm{s}}$, between two plates of the slant connection was also needed. Therefore, the friction test was again carried out to determine the friction coefficient of connections. Figure 13 presents the setting of the friction test based on the Coulomb friction concept on the inclined surface. The self-weight of the side beam was $0.08826 \mathrm{kN}$ with a connection slanting angle of $45^{\circ}\left(\theta=45^{\circ}\right)$. The overall weight on top of the side beam was obtained as $0.14164 \mathrm{kN}$. As shown in Figure 13, a load cell of $1 \mathrm{kN}$ capacity had been located at the right side of the beam to measure the value of the sliding force. An automated digital data logger (Phidget 4 bridge- interface kit) was used to measure the corresponding axial force. The friction test measured a magnitude of $0.42\left(\mu_{s}=\tan \varphi\right)$ for the static friction coefficient of the inclined surfaces. After finding the friction coefficient, the components of the full-scale specimen were installed between two rigid columns that provided fixed-end supports, similar to the analytical assumption. The test was carried out at two different temperatures, before and after elevated temperatures. In the idealised models in the analytical and numerical methods, the value of the elevated temperature was considered uniform. 
Therefore, in the experimental tests, a steady-state heating trend was employed. The heat application was carried out for a few minutes to ensure the uniformity of temperature throughout the beam.

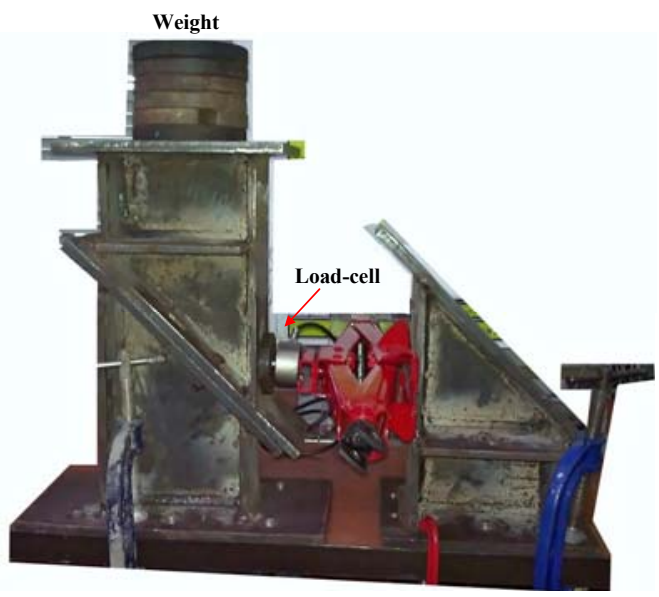

Figure 13. Friction Test to Determine the Static Friction Factor $\left(\mu_{s}\right)$ between the Two Faces of Slant End-plate Connection (Full-scale Specimen)

A series of tests were conducted to verify the analytical outcomes. Figure 14 shows one of the typical cases. As shown in this figure, the axial forces were measured by a $5 \mathrm{kN}$ (capacity) load cell located at the side beam. The measured values were recorded by a digital data logger board (Phidget 4 Bridge) that was linked to a computer. For the heating system, an electrical heating element was installed on the web so that the required temperature can be controlled by a control box. To keep the temperature within $100{ }^{\circ} \mathrm{C}$ or elastic zone [18], one thermocouple set was attached to the main beam. The thermal sensor of this set was connected to a digital screen board in the control box so that the maximum temperature for the heating system can be imposed. The performance of the steel beam was investigated under 13 symmetric gravity load intensities $(0.215 \mathrm{kN}, 0.382 \mathrm{kN}, 0.549 \mathrm{kN}, 0.828 \mathrm{kN}, 1.043 \mathrm{kN}$, $1.195 \mathrm{kN}, 1.303 \mathrm{kN}, 1.503 \mathrm{kN} 1.703 \mathrm{kN}, 1.903 \mathrm{kN}, 2.003 \mathrm{kN}, 2.103 \mathrm{kN}$ and $2.203 \mathrm{kN}$ ). The results from the experimental studies were compared at certain loadings with the analytical models. Figure 15 shows the relationships between applied loads and axial forces in the beam at two different thermal conditions: before and after elevated temperatures. It is evidenced that the analytical models conform acceptably to the results produced by experiments, both before and after temperature increase.

\subsubsection{Non-symmetric gravity load test}

In the non-symmetric case study, the beam specimen was tested under a group of weights for two different load distributions in terms of resultant gravity load location on the beam. With the analytical equation (Equation 5) the values of $a$ can be determined for both before and after sliding cases for the full-scale specimen: these values were obtained as 0.65 and 0.8 , respectively. Similarly, the beam was tested for several incrementally applied non-symmetric gravity loads with three sub-cases: before (two cases) and after elevated temperature. During the test, the axial force was recorded with a force sensor located at the end of the side beam and an interface kit system (model 8/8) attached to a computer. The aim was the same, i.e., to measure axial force in the beam for incremental load magnitudes. For the current tests, the distances from the centre of mass of non-symmetric gravity load to the right support were $0.65 \mathrm{~L}$ and $0.8 \mathrm{~L}$ for the cases of before and after sliding, respectively. The beam of a full-scale 
specimen was tested at room and elevated temperatures. A thermocouple set was used to measure the applied temperature. The heat source from an electrical element was placed in the middle of the beam web. The experimental results were compared with the analytical results. Figure 16 illustrates a comparison between the analytical and experimental methods based on the relationships between applied non-symmetric gravity loads and the axial forces in the steel beam, for various sliding and thermal conditions.
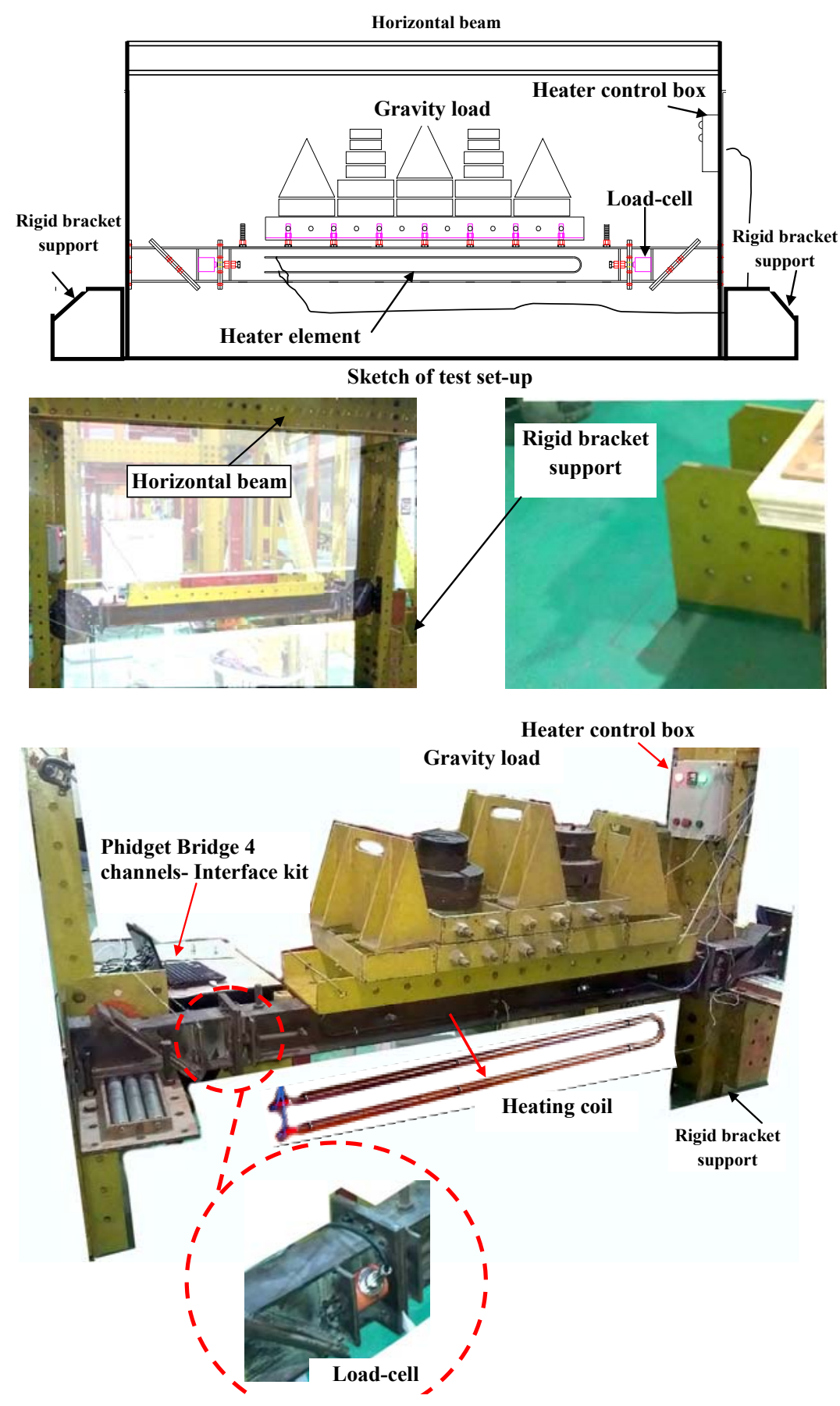

Figure 14. Test Set-up for full-scale Specimen with $\theta=45^{\circ}$ under Symmetric Gravity Load 


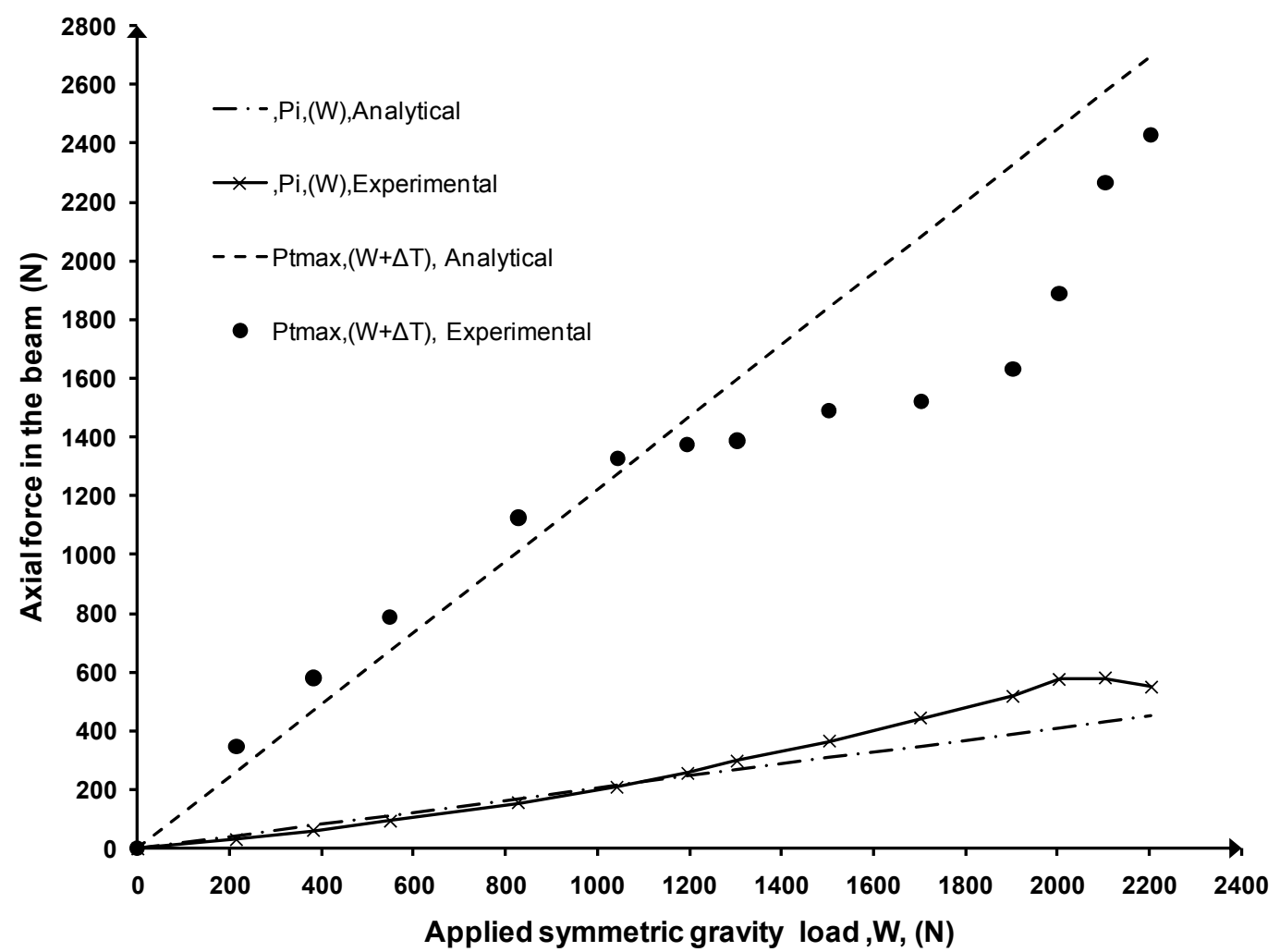

Figure 15. The Relationship between Symmetric Gravity Load and Axial Force in the Beam for Full-scale Specimen (friction factor, $\mu_{s}=\tan \Phi=0.42, \theta=45^{\circ}$ )

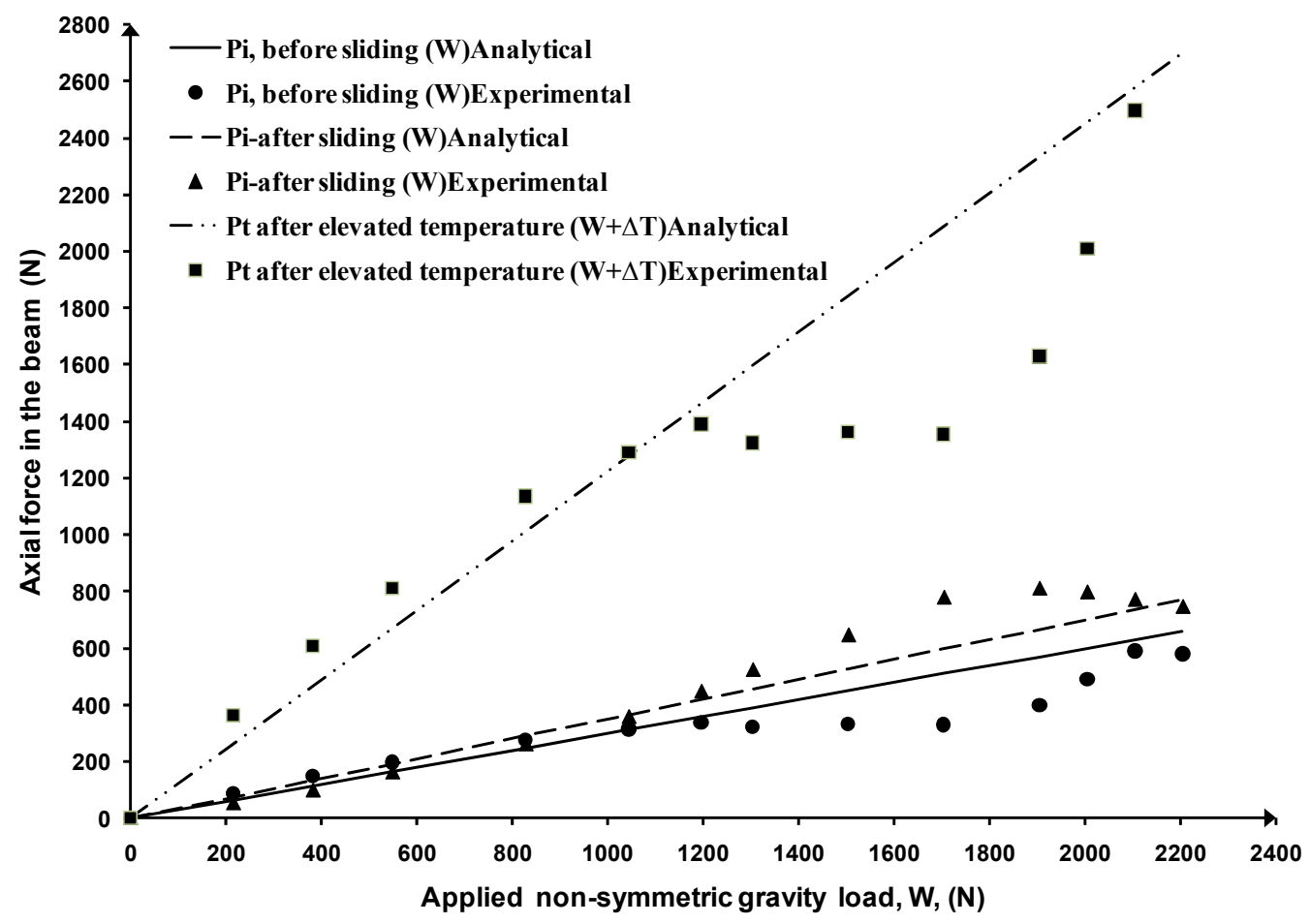

Figure 16. Relationship between Non-symmetric Load and Axial Force in the Full-scale Specimen (friction factor, $\mu_{s}=\tan \varphi=0.42, \theta=45^{\circ}$ ) 
In the experimental study, two specimens with different sizes were designed to verify the primary hypothesis on the performance of the proposed connection. On the other hand, structural behaviour was simulated and examined by an analytical approach. Equation 6 is adopted to determine the comparison ratio of analytical to test results where $P$ is the measured axial force under various boundary conditions such as $P_{i}$ or $P_{t}$ and $n$ is the number of tests under various gravity loads.

$R_{\text {average-ratio }}=\sum_{i=1}^{n} \frac{\left(\frac{P_{i(\text { Analytical })}}{P_{i(\text { test })}}\right)}{n}$

The comparison ratio for the small-scale specimen is 0.97 under symmetric gravity load only. However, after an increase in temperature, this ratio is computed as 1.08. Under nonsymmetric gravity load, the ratio ranges from 1.00 to 1.02 . From the full-scale specimen, the comparison ratios are between 0.96 and 1.09 .

\section{CONCLUSION}

In this research, a series of experimental tests was conducted for steel beams with a $45^{\circ}$ slanting angle of end-plate connection to validate the results obtained from the analytical approach, where two sets of specimens were fabricated for tests: a small-scale and a real-scale physical models.

The test results were in consistency with those of analytical for both the small-scale and realscale specimens within an acceptable range of agreement. Therefore, the models can predict satisfactorily the behaviour of a steel beam with slant end-plate connections in various boundary conditions.

It is concluded that the axial load-bearing capacity of a steel beam under symmetric gravity load is higher than that under non-symmetric load at room temperature. On the other hand, the axial load-bearing capacity of this beam is identical under elevated temperature conditions for both symmetric and non-symmetric gravity loads.

\section{ACKNOWLEDGEMENTS}

The research was financially supported by the School of Graduate Studies (SPS), Universiti Teknologi Malaysia (PY/2012/00977).

\section{REFERENCES}

[1] Rodrigues, J.P.C., Cabrita Neves, I. and Valente, J.C., "Experimental Research on the Critical Temperature of Compressed Steel Elements with Restrained Thermal Elongation", Fire Safety Journal, 2000, Vol. 35, No. 2, pp. 77-98.

[2] Mourão, H.D.R. and E Silva, V.P., "On the Behaviour of Single-span Steel Beams under Uniform Heating", Journal of the Brazilian Society of Mechanical Sciences and Engineering, 2007, Vol. 29, No. 1, pp. 115-122. 
[3] Wong, M.B., Modelling of Axial Restraints for Limiting Temperature Calculation of Steel Members in Fire", Journal of Constructional Steel Research, 2005, Vol. 61, No. 5, pp. 675-687.

[4] Usmani, A.S., Rotter, J.M., Lamont, S., Sanad, A.M. and Gillie, M., "Fundamental Principles of Structural Behaviour under Thermal Effects", Fire Safety Journal, 2001, Vol. 36, No. 8, pp. 721-744.

[5] Bailey, C.G., Burgess, I.W. and Plank, R.J., "Analyses of the Effects of Cooling and Fire Spread on Steel-framed Buildings", Fire Safety Journal, 1996, Vol. 26, No. 4, pp. 273-293.

[6] Larson, S.C. and Van Geem, M.G., "Structural Thermal Break Systems for Buildings: Feasibility Study: Final Report, in Other Information: Portions of this Document are Illegible in Microfiche Products", Original Copy Available until Stock is Exhausted, 1987, pp. Medium: X, Size: Pages: 102.

[7] Bradford, M., "Elastic Analysis of Straight Members at Elevated Temperatures. Advances in Structural Engineering, 2006, Vol. 9, No. 5, pp. 611-618.

[8] Takagi, J. and Deierlein, G.G., "Strength Design Criteria for Steel Members at Elevated Temperatures", Journal of Constructional Steel Research, 2007, Vol. 63, No. 8, pp. 1036-1050.

[9] Yuan, Z., Tan, K.H. and Ting, S.K., "Testing of Composite Steel Top-and-seat-andweb Angle Joints at Ambient and Elevated Temperatures, Part 1: Ambient Tests", Engineering Structures, 2011, Vol. 33, No. 10, pp. 2727-2743.

[10] Sarraj, M., Burgess, I., Davison, J. and Plank, R., "Finite Element Modelling of Steel Fin Plate Connections in Fire", Fire Safety Journal, 2007, Vol. 42, No. 6, pp. 408-415.

[11] Mao, C., Chiou, Y.-J., Hsiao, P.-A. and Ho, M.-C., "Fire Response of Steel Semi-rigid Beam-column Moment Connections", Journal of Constructional Steel Research, 2009, Vol. 65, No. 6, pp. 1290-1303.

[12] Yu, H., Burgess, I., Davison, J. and Plank, R., "Experimental and Numerical Investigations of the Behavior of Flush End Plate Connections at Elevated Temperatures", Journal of Structural Engineering, 2010, Vol. 137, No. 1, pp. 80-87.

[13] Díaz, C., Martí, P., Victoria, M. and Querin, O.M., "Review on the Modelling of Joint Behaviour in Steel Frames", Journal of Constructional Steel Research, 2011, Vol. 67, No. 5, pp. 741-758.

[14] Lin, S., Huang, Z. and Fan, M., "Modelling of End-Plate Connections in Fire, in Design, Fabrication and Economy of Metal Structures. 2013, Springer. pp. 321-326.

[15] Lin, S., Huang, Z. and Fan, M., "Modelling Partial End-plate Connections under Fire Conditions", Journal of Constructional Steel Research, 2014, Vol. 99, pp. 18-34.

[16] Zahmatkesh, F., Osman, M.H. and Talebi, E., "Thermal Behaviour of Beams with Slant End-Plate Connection Subjected to Nonsymmetric Gravity Load", The Scientific World Journal, 2014. 2014.

[17] Zahmatkesh, F., Osman, M.H., Talebi, E. and Kueh, A.B.H., "Analytical Study of Slant End-plate Connection subjected to Elevated Temperatures", Steel and Composite Structures, 2014, Vol. 17, No. 1, pp. 47-67.

[18] EC3, Eurocode 3 (EC3), BS EN 1993-1-2: Design of Steel Structures, Part 1-2: General Rules-Structural Fire Design. . 2005, British Standards Institution London, UK.

[19] Zahmatkesh, F., Osman, M.H., Talebi, E. and Kueh, A.B.H., "Direct Stiffness Model of Slant Connection under Thermal and Non-symmetric Gravity Load", Journal of Constructional Steel Research, 2014, Vol. 102, No. 0, pp. 24-43. 